\title{
Activity of siderophores against drug-resistant Gram-positive and Gram-negative bacteria
}

\author{
Karuna Gokarn ${ }^{1,2}$ \\ Ramprasad B Pal' \\ 'Department of Microbiology, Sir \\ Hurkisondas Nurrotumdas Medical \\ Research Society, ${ }^{2}$ Caius Research \\ Laboratory, St Xavier's College, \\ Mumbai, India
}

This article was published in the following Dove Press journal: Infection and Drug Resistance

\begin{abstract}
Infections by drug-resistant bacteria are life-threatening. As iron is a vital element for the growth of bacteria, iron-chelating agents (siderophores) can be used to arrest their multiplication. Exogenous siderophores - exochelin-MS and deferoxamine-B - were evaluated for their inhibitory activity against methicillin-resistant Staphylococcus aureus and metallo- $\beta$-lactamase producers - Pseudomonas aeruginosa and Acinetobacter baumannii - by disc diffusion, microbroth dilution, and turbidimetric growth assays. The drug-resistant isolates were inhibited by the synergistic activity of siderophores and antibiotics. Minimum inhibitory concentration of exochelin-MS+ampicillin for different isolates was between 0.05 and $0.5 \mathrm{mg} / \mathrm{mL}$. Minimum inhibitory concentration of deferoxamine-B+ampicillin was $1.0 \mathrm{mg} / \mathrm{mL}$ and greater. Iron-chelation therapy could provide a complementary approach to overcome drug resistance in pathogenic bacteria.
\end{abstract}

Keywords: iron-chelation, xenosiderophores, exochelin MS, deferoxamine B

\section{Introduction}

Most nosocomial infections are caused by Gram-positive methicillin-resistant Staphylococcus aureus (MRSA) and Gram-negative metallo- $\beta$-lactamase (MBL)-producing bacteria such as Pseudomonas aeruginosa and Acinetobacter baumannii. Emergence of drug resistance in such pathogens has made treatment difficult, making exploration of new therapeutic options imperative. As iron is an essential cofactor of many important biochemical pathways for all cells, one possible strategy would be to impose an iron-deficient environment on these pathogens.

Iron is acquired by microorganisms from the environment with the help of siderophores that are taken up via species-specific receptors. Xenosiderophores ("Xeno" - not "self") are exogenous siderophores, and when $\mathrm{Fe}^{3+}$ ion is complexed with these, iron uptake may be affected because of the absence of receptors. Exochelin-MS (Exo-MS) is a siderophore produced by Mycobacterium smegmatis and deferoxamine-B (DFO-B) is a siderophore made by Streptomyces pilosus (now available commercially). These two are xenosiderophores for MRSA and for MBL-producing bacteria, and therefore, the effect of Exo-MS and DFO-B on these pathogens was determined by disc diffusion, micro-broth dilution, and turbidimetric growth assays.

The isolates of $S$. aureus, $P$. aeruginosa, and A. baumannii confirmed as drug resistant were used to assess the susceptibility to siderophores. Twenty isolates of MRSA, 15 isolates of MBL-producing $P$. aeruginosa, and 15 isolates of MBL-producing A. baumannii (a total of 50 isolates) were used in this study.
Correspondence: Karuna Gokarn Department of Microbiology, Sir Hurkisondas Nurrotumdas Medical Research Society, LT Marg, Mumbai 400 002, India Email karuna.gokarn@xaviers.edu 


\section{Materials and methods Identification of MRSA and MBL- producing $P$. aeruginosa and $A$. baumannii (MBL producers)}

A large number of clinical isolates of $S$. aureus, P. aeruginosa and A. baumannii were procured from the Microbiology Laboratory of Sir H.N. Hospital, Mumbai. Identification of the isolates based on the morphological and biochemical parameters was carried out at Sir H.N. Medical Research Centre, Mumbai.

S. aureus isolates were identified as methicillin-resistant by the following tests:

Oxacillin disc susceptibility test: Mueller-Hinton agar (MHA) plates supplemented with $4 \% \mathrm{NaCl}$ were inoculated with the isolates whose turbidity was adjusted to $0.5 \mathrm{McFar}-$ land standard. A $1.0 \mu \mathrm{g}$ oxacillin disc and a $30 \mu \mathrm{g}$ cefoxitin disc were placed on the seeded agar surface and incubated at $37^{\circ} \mathrm{C}$ for $18 \mathrm{~h} .{ }^{1,2}$ The isolate resistant to either or both the antibiotics was selected for further tests (Table S1).

Commercially available oxacillin E test strip (Biomerieux) on MHA plates supplemented with $2 \% \mathrm{NaCl}$ was used to determine the minimum inhibitory concentration (MIC) for the isolates. ${ }^{3}$

The latex agglutination test was carried out for the detection of $m e c A$ gene product PBP2A (Biomerieux Slidex MRSA agglutination kit) in the isolates. ${ }^{1}$

$P$. aeruginosa and $A$. baumannii isolates were identified as MBL producers by the following EDTA-based microbiological tests:

\section{EDTA+imipenem/ceftazidime combination assay}

Extracts of each isolate were prepared by lysing cells in $50 \mathrm{mM}$ Tris $-\mathrm{HCl}$ buffer $(\mathrm{pH}=8)$ by repeated cycles of freezing and thawing at $-20^{\circ} \mathrm{C}$ and $37^{\circ} \mathrm{C}$, respectively. The supernatant was used as the crude enzyme extract to detect the presence of MBLs. ${ }^{4}$ MBLs are distinguished from serinecarbapenemases by evaluating the effect of EDTA on the growth of the carbapenem-sensitive strain of Escherichia coli ATCC 25922 in the presence of a carbapenem.

Culture suspension of E. coli ATCC 25922 adjusted to 0.5 McFarland standard was swabbed uniformly on MHA plate. A $10 \mu \mathrm{g}$ imipenem or a $30 \mu \mathrm{g}$ ceftazidime disc (Himedia, India) was placed on the center of the seeded agar plate.

Four sterile filter paper discs containing different solutions as given below were placed at the periphery of the central disc at $10 \mathrm{~mm}$ edge-to-edge distance:

- Disc 1: $20 \mu \mathrm{L}$ of the crude enzyme extract;
- Disc 2: $20 \mu \mathrm{L}$ of the same extract and $0.1 \mathrm{mM} \mathrm{ZnSO}_{4}$;

- Disc 3: $20 \mu \mathrm{L}$ of the same extract and $20 \mathrm{mM}$ EDTA $(\mathrm{pH}=8)$;

- Disc 4: $20 \mu \mathrm{L} 50 \mathrm{mM}$ Tris $\mathrm{HCl}$ buffer $(\mathrm{pH}=8)$.

After incubation at $37^{\circ} \mathrm{C}$ for $18 \mathrm{~h}$, the zone of inhibition around each disc was measured.

\section{EDTA-double disc synergy test}

Culture suspensions of E. coli ATCC 25922 (control) and the P. aeruginosa and A. baumannii isolates adjusted to $0.5 \mathrm{McFar}-$ land standard were swabbed individually on MHA plates. A $10 \mu \mathrm{g}$ imipenem disc was placed on the agar surface. A blank disc with $10 \mu \mathrm{L}$ of sterile $0.5 \mathrm{mM}$ EDTA $(750 \mu \mathrm{g})$ was placed at a $10 \mathrm{~mm}$ edge-to-edge distance from the imipenem disc. Similarly, a $30 \mu \mathrm{g}$ ceftazidime and an EDTA disc $(750 \mu \mathrm{g})$ were placed on the same plate. ${ }^{5}$ After incubation at $37^{\circ} \mathrm{C}$ for $18 \mathrm{~h}$, the zone of inhibition around each disc was measured.

\section{Modified Hodge test for carbapenemase detection}

Here, carbapenem inactivation by a carbapenemase-producing strain was tested along with a carbapenem-sensitive E. coli strain ATCC 25922. A culture suspension of E. coli ATCC 25922 adjusted to $0.5 \mathrm{McFarland}$ standard was swabbed on MHA plates. A $10 \mu \mathrm{g}$ imipenem disc was placed at the center of the plate and an isolate of P. aeruginosa or $A$. baumannii was streaked from the edge of the disc to the periphery of the plate in four different directions. ${ }^{5}$ The zone of inhibition was recorded after incubation at $37^{\circ} \mathrm{C}$ for $18 \mathrm{~h}$.

\section{Determination of in vitro effect of Exo-MS and DFO-B on MRSA and

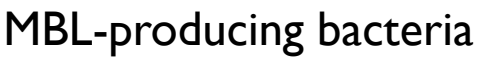

Confirmed isolates of MRSA and MBL-producing P. aerugi$n o s a$ and $A$. baumannii were used for determining the effect of siderophores.

Exo-MS was extracted, purified, and analyzed in our laboratory. ${ }^{6}$ The concentration of Exo-MS was $19 \mathrm{mg} / \mathrm{mL}$. DFO$\mathrm{B}$, which is commercially available (Desferal, Novartis), was procured in powder form and reconstituted in sterile distilled water at a concentration of $250 \mathrm{mg} / \mathrm{mL}$. Both the siderophores tested were in desferri (non- $\mathrm{Fe}^{3+}$ bound) forms. The in vitro effect of Exo-MS and DFO-B on drug-resistant pathogenic bacteria was determined by the following methods:

\section{Disc diffusion method}

The antibacterial susceptibility testing was performed as per the Clinical and Laboratory Standards Institute (CLSI) 
recommendations (Kirby-Bauer method), ${ }^{7}$ using standard antibiotic discs (HiMedia, India) in combination with siderophores. The standard antibiotic discs contained $10 \mu \mathrm{g}$ of ampicillin, imipenem, meropenem, and $5 \mu \mathrm{g}$ of cefdinir. For MRSA, ampicillin and cefdinir discs were used. For MBL producers, ampicillin, imipenem, and meropenem discs were used. On each antibiotic disc, $10 \mu \mathrm{L}$ of $5 \mathrm{mg} / \mathrm{mL}$ Exo-MS solution or $10 \mu \mathrm{L}$ of $10 \mathrm{mg} / \mathrm{mL}$ DFO-B solution was loaded. As a control, $10 \mu \mathrm{L}$ of sterile distilled water was loaded on the antibiotic discs.

Culture suspensions of MRSA and MBL-producing $P$. aeruginosa and $A$. baumannii isolates adjusted to 0.5 McFarland standard were swabbed uniformly on MHA plate. The sterile antibiotic discs were placed on the surface of the seeded agar plate. After incubation at $37^{\circ} \mathrm{C}$ for $18 \mathrm{~h}$, the zone of inhibition around each disc was measured.

\section{MIC determination}

For each isolate, MIC was determined by micro-broth dilution method in triplicates in 96-well microtiter plates using Mueller-Hinton broth (MHB) No. 2 with control cations (HiMedia, Mumbai, India). The total volume in each well was $200 \mu \mathrm{L}$ and the plates were incubated at $37^{\circ} \mathrm{C}$ for $24 \mathrm{~h}$.

To determine MIC of siderophores, 0.05, 0.125, 0.25, and $0.5 \mathrm{mg} / \mathrm{mL}$ of Exo-MS was used individually and in combination with ampicillin for MRSA and MBL-producing isolates. Similarly, $0.5,1,2.5,5,7.5$, and $10 \mathrm{mg} / \mathrm{mL}$ of DFO-B was used individually and in combination with ampicillin for MRSA and MBL-producing isolates. The concentration of ampicillin was kept constant at $0.01 \mathrm{mg} / \mathrm{mL}$ as recommended by CLSI.

Medium control contained $200 \mu \mathrm{L}$ MHB without any isolate, growth control contained $200 \mu \mathrm{L}$ MHB with each isolate, and ampicillin control contained $200 \mu \mathrm{L}$ MHB+ampicillin with each isolate. Ferric ammonium citrate at a final concentration of $0.5 \mathrm{mg} / \mathrm{mL}$ was used for each isolate as "Fe" control. Each experiment mentioned above was carried out three times.

The turbidity of each well at the end of $24 \mathrm{~h}$ at $37^{\circ} \mathrm{C}$ was measured on a microplate reader at $620 \mathrm{~nm}$. The lowest concentration of the Exo-MS or DFO-B that did not allow growth of the isolate was the MIC of the siderophore.

To determine whether the siderophore concentration had a bacteriostatic or a bactericidal effect, a loopful of broth from each well showing no growth after $24 \mathrm{~h}$ was streaked onto MHA plates and incubated at $37^{\circ} \mathrm{C}$ for $24 \mathrm{~h}$.

\section{Turbidimetric assay}

The growth curves of two isolates of MRSA and six MBL producers were determined in the presence of Exo-MS or
DFO-B. Here too, the concentration of ampicillin was kept constant at $0.01 \mathrm{mg} / \mathrm{mL}$. The growth assay was carried out in 96-well microtiter plates, each well having a total volume of $200 \mu \mathrm{L}$ for each isolate. The different concentrations of siderophores and their antibiotic combinations were used as described for MIC determination, in triplicate. Each plate was incubated at $37^{\circ} \mathrm{C}$ with continuous shaking in Epoch 2 Microplate Spectrophotometer (Biotek, Winooski, VT, USA). Optical density (OD) of each well was monitored at $620 \mathrm{~nm}$ every hour for $24 \mathrm{~h}$.

\section{Results \\ In vitro inhibitory effect of Exo-MS and DFO-B on MRSA and MBL producers}

\section{Disc diffusion method}

Figure 1 shows representative examples of zones of inhibition of MRSA by Exo-MS, DFO-B, and their combinations with antibiotics. No zone of inhibition with standard antibiotic disc was observed when $10 \mu \mathrm{L}$ of distilled water was loaded instead of siderophores (Figure 1, second row, left plate). The same plate also shows that the zone of inhibition was negligible when ferric ammonium citrate was added to the ampicillin disc along with DFO-B.

Figure 2 shows representative examples of zones of inhibition for MBL-producing $P$. aeruginosa by Exo-MS, DFO-B, and their combinations with antibiotics.

Figure 3 shows representative examples of zones of inhibition for MBL-producing A. baumannii by Exo-MS, DFO-B, and their combinations with antibiotics.

Zones of inhibition with Exo-MS, DFO-B, and their combination with antibiotics for all the isolates tested are given in Tables S2-S4.

Table 1 shows the percentage of isolates that were susceptible to the combined effect of siderophores+antibiotics by the disc diffusion method.

\section{MIC of Exo-MS and DFO-B}

For each isolate, growth was observed in growth control and controls containing only ampicillin. For MRSA, MICs of Exo-MS alone and in combination with ampicillin were between 0.05 and $0.5 \mathrm{mg} / \mathrm{mL}$. For P. aeruginosa, MIC of Exo-MS alone was $0.125 \mathrm{mg} / \mathrm{mL}$ and MICs of Exo-MS+ampicillin combination were between 0.05 and $0.125 \mathrm{mg} / \mathrm{mL}$. For A. baumannii, MICs of Exo-MS alone and in combination with ampicillin were between 0.05 and $0.25 \mathrm{mg} / \mathrm{mL}$ (Table 2).

For MRSA, MICs of DFO-B alone were between 7.5 and $10 \mathrm{mg} / \mathrm{mL}$. MICs of DFO-B+ampicillin combination 

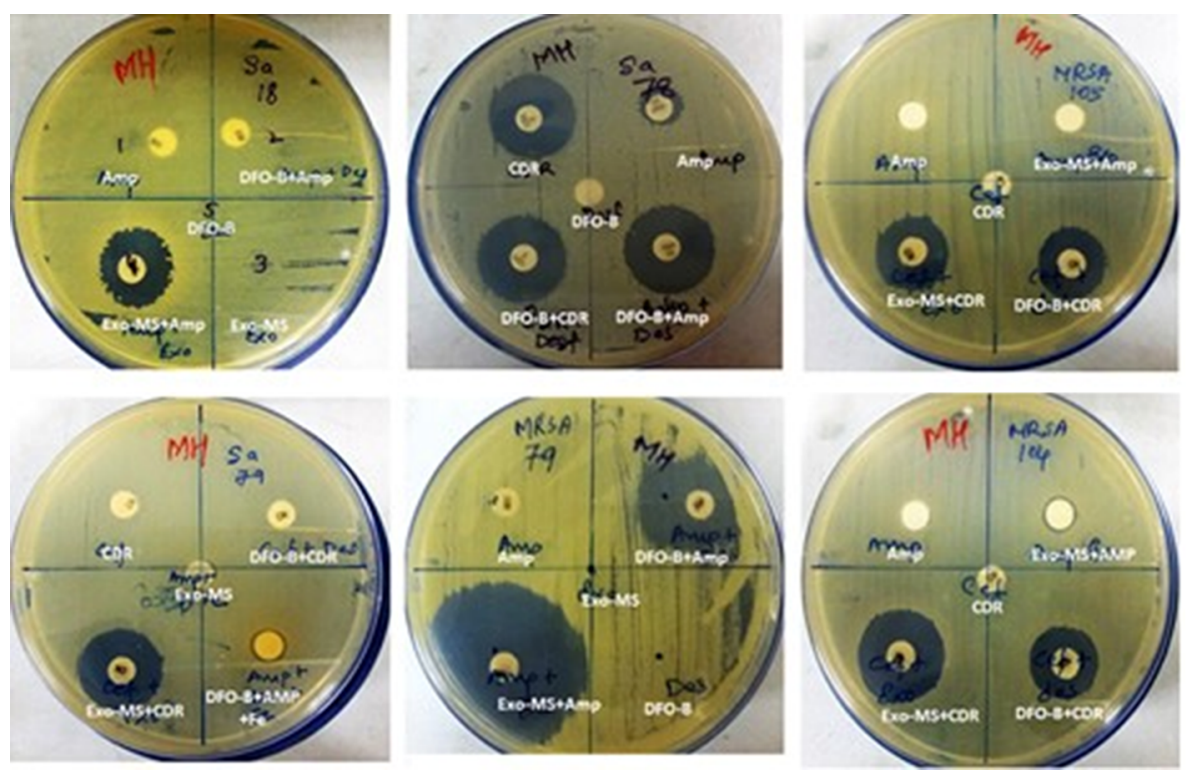

Figure I Susceptibility of MRSA to siderophores and antibiotics.

Notes: MRSA isolates were swabbed on the surface of MHA plates and antibiotic discs were placed. Then, either Exo-MS or DFO-B (I0 $\mu \mathrm{L}$ each) was loaded onto the antibiotic discs. The antibiotics used were Amp and CDR. On each plate, a different isolate was seeded. Zones of inhibition were observed with the siderophore+antibiotic combinations, indicating synergism. For example, in the second row, the left plate showed no zones of inhibition with cefdinir. The cefdinir disc was loaded with $10 \mu \mathrm{L}$ of distilled water. The siderophore+cefdinir combination showed a zone of inhibition. Exo-MS and DFO-B individually showed no zones of inhibition. The zone of inhibition was negligible when the disc was loaded with ferric ammonium citrate along with DFO-B on the Amp disc.

Abbreviations: Amp, ampicillin; CDR, cefdinir; DFO-B, deferoxamine-B; Exo-MS, exochelin-MS; MRSA, methicillin-resistant Staphylococcus aureus; MHA, Mueller-Hinton agar.
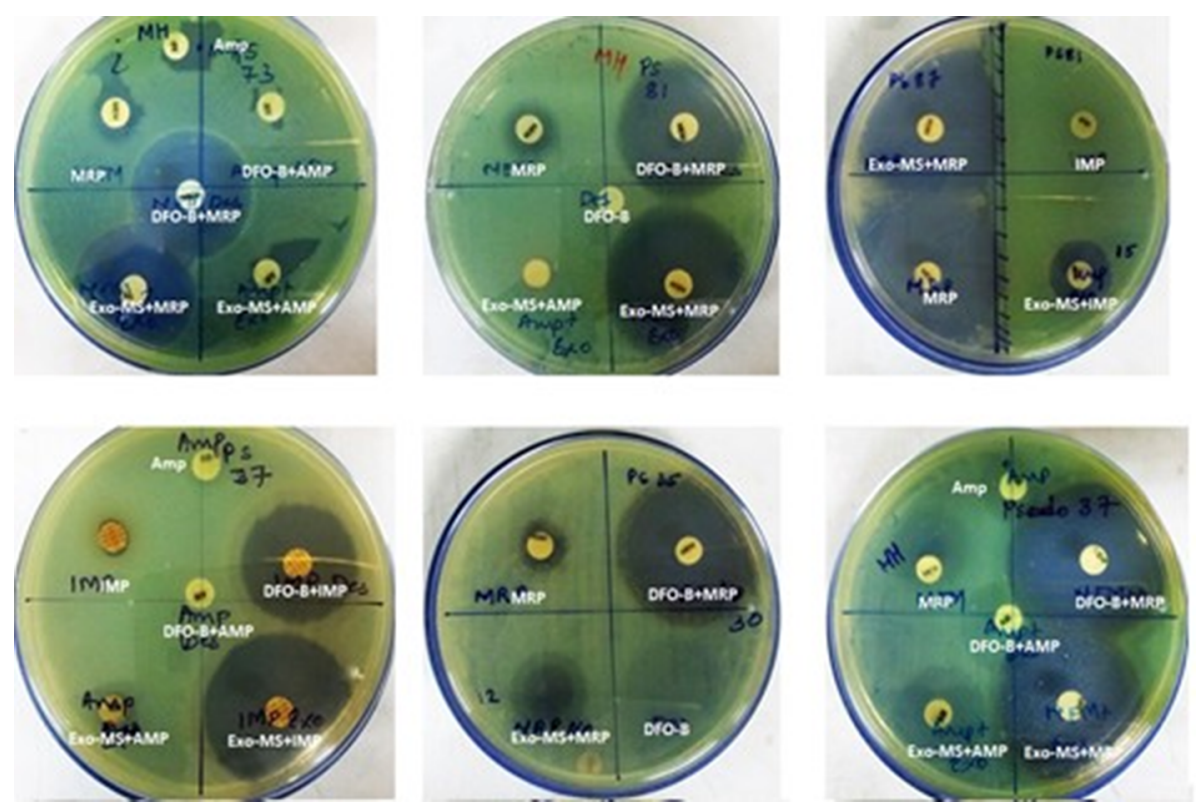

Figure 2 Susceptibility of metallo- $\beta$-lactamase-producing Pseudomonas aeruginosa to siderophores and antibiotics.

Notes: $P$. aeruginosa isolates were swabbed on the surface of MHA plates and antibiotic discs were placed. Then, either Exo-MS or DFO-B (I0 $\mu \mathrm{L}$ each) was loaded onto the antibiotic disc. The antibiotics used were Amp, IMP, and MRP. On each plate, a different isolate was seeded. Larger zones of inhibition were observed with the siderophore+antibiotic combinations, indicating synergism. Such an effect is seen in the first row, middle plate for siderophore+meropenem combinations, where meropenem alone shows a small zone of inhibition; Exo-MS and DFO-B individually showed no zones of inhibition.

Abbreviations: Amp, ampicillin; DFO-B, deferoxamine-B; Exo-MS, exochelin-MS; IMP, imipenem; MHA, Mueller-Hinton agar; MRP, meropenem.

were between 5 and $10 \mathrm{mg} / \mathrm{mL}$. For P. aeruginosa, MICs of DFO-B alone were between 5 and $10 \mathrm{mg} / \mathrm{mL}$. MICs of DFOB+ampicillin combination were between 2.5 and $10 \mathrm{mg} / \mathrm{mL}$. For A. baumannii, MICs of DFO-B alone were between 2.5 and $10 \mathrm{mg} / \mathrm{mL}$. MICs of DFO-B+ampicillin combination were between 1.0 and $10 \mathrm{mg} / \mathrm{mL}$ (Table 3).

When a loopful of broth from wells showing no growth was re-streaked on MHA plates and incubated at $37^{\circ} \mathrm{C}$ for 

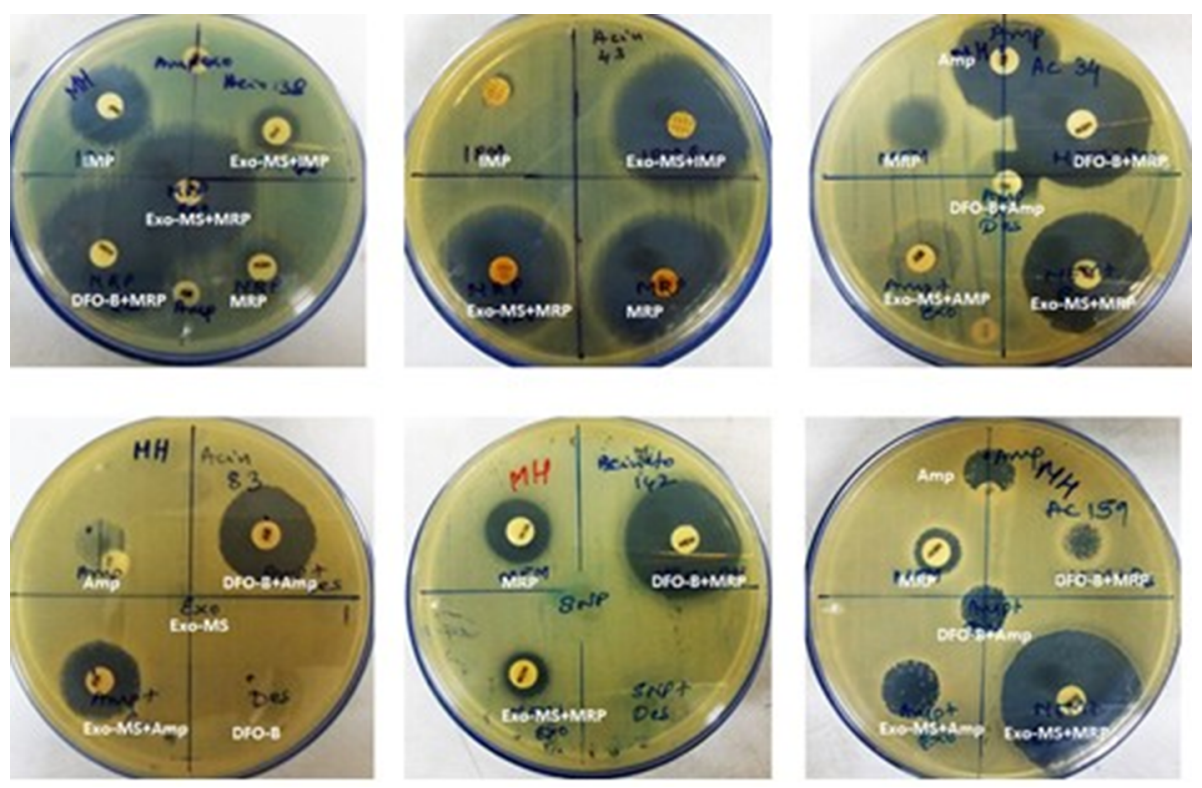

Figure 3 Susceptibility of metallo- $\beta$-lactamase-producing Acinetobacter baumannii to siderophores and antibiotics.

Notes: A. baumannii isolates were swabbed on the surface of MHA plates and antibiotic discs were placed. Then, either Exo-MS or DFO-B (IO $\mu \mathrm{L}$ each) were loaded onto the antibiotic discs. The antibiotics used were Amp, IMP, and MRP. On each plate, a different isolate was seeded. Zones of inhibition were observed with the siderophore+antibiotic combinations, indicating synergism. For example, in the second row, the left plate showed no zones of inhibition with ampicillin and siderophores individually. The siderophore+ampicillin combination showed zones of inhibition. Exo-MS and DFO-B individually showed no zones of inhibition.

Abbreviations: Amp, ampicillin; DFO-B, deferoxamine-B; Exo-MS, exochelin-MS; IMP, imipenem; MHA, Mueller-Hinton agar; MRP, meropenem.

Table I Percent susceptibility of drug-resistant Gram-positive MRSA and Gram-negative MBL producers to combinations of Exo-MS and DFO-B with antibiotics by the disc diffusion method

\begin{tabular}{llll}
\hline Pathogen & Standard antibiotics & $\begin{array}{l}\text { Isolates susceptible to } \\
\text { combination of Exo-MS + } \\
\text { antibiotic (\%) }\end{array}$ & $\begin{array}{l}\text { Isolates susceptible to } \\
\text { combination of DFO-B + } \\
\text { antibiotic (\%) }\end{array}$ \\
\hline MRSA ( $=20)$ & Ampicillin $(0.01 \mathrm{mg})$ & $15(75)$ & $10(50)$ \\
& Cefdinir $(0.005 \mathrm{mg})$ & $5(33)$ & $1(05)$ \\
MBL-producing Pseudomonas & Ampicillin $(0.01 \mathrm{mg})$ & $4(27)$ & $5(33)$ \\
aeruginosa ( $\mathrm{n}=15)$ & Imipenem (0.01 mg) & $7(47)$ & $8(53)$ \\
& Meropenem $(0.01 \mathrm{mg})$ & $9(60)$ & $6(40)$ \\
MBL-producing Acinetobacter & Ampicillin $(0.01 \mathrm{mg})$ & $7(47)$ & $6(40)$ \\
baumannii $(\mathrm{n}=15)$ & Imipenem $(0.01 \mathrm{mg})$ & $7(47)$ & $8(53)$ \\
& Meropenem $(0.01 \mathrm{mg})$ & $10(67)$ & $10(67)$ \\
\hline
\end{tabular}

Abbreviations: DFO-B, deferoxamine-B; Exo-MS, exochelin-MS; MBL, metallo- $\beta$-lactamase; MRSA, methicillin-resistant Staphylococcus aureus.

Table 2 MIC of Exo-MS for MRSA and MBL-producing Pseudomonas aeruginosa and Acinetobacter baumannii

\begin{tabular}{|c|c|c|c|c|c|c|c|c|c|c|}
\hline \multirow[t]{2}{*}{ Isolates } & \multicolumn{4}{|c|}{$\begin{array}{l}\text { Number of isolates inhibited at } \\
\text { Exo-MS }(\mathrm{mg} / \mathrm{mL})\end{array}$} & \multirow[t]{2}{*}{$\begin{array}{l}\text { Total isolates } \\
\text { inhibited (\%) }\end{array}$} & \multicolumn{4}{|c|}{$\begin{array}{l}\text { Number of isolates inhibited at Exo-MS } \\
(\mathrm{mg} / \mathrm{mL})+\text { ampicillin } 0.01 \mathrm{mg} / \mathrm{mL}\end{array}$} & \multirow[t]{2}{*}{$\begin{array}{l}\text { Total isolates } \\
\text { inhibited (\%) }\end{array}$} \\
\hline & 0.05 & 0.125 & 0.25 & 0.5 & & 0.05 & 0.125 & 0.25 & 0.5 & \\
\hline MRSA $(n=20)$ & 4 & 6 & 2 & 1 & $13(65)$ & 6 & 6 & 2 & 1 & $15(75)$ \\
\hline MBL-producing & 0 & 3 & 0 & 0 & $3(20)$ & I & 3 & 0 & 0 & $4(27)$ \\
\hline \multicolumn{11}{|l|}{ P. aeruginosa $(n=15)$} \\
\hline MBL-producing & I & 2 & 2 & 0 & $5(33)$ & 3 & 2 & 2 & 0 & $7(47)$ \\
\hline A. baumannii $(n=15)$ & & & & & & & & & & \\
\hline
\end{tabular}

Notes: MIC was determined by adding Exo-MS at different concentrations with or without ampicillin at $0.0 \mathrm{l} \mathrm{mg} / \mathrm{mL}$. The number of isolates inhibited at the end of $24 \mathrm{~h}$ at $37^{\circ} \mathrm{C}$ are shown. $\mathrm{n}=$ total number of isolates of each pathogen. Medium control showed no growth, whereas growth control, ampicillin control, and "Fe" control showed growth (data not shown).

Abbreviations: Exo-MS, exochelin-MS; MBL, metallo- $\beta$-lactamase; MIC, minimum inhibitory concentration; MRSA, methicillin-resistant Staphylococcus aureus. 
Table 3 MIC of DFO-B for MRSA and MBL-producing Pseudomonas aeruginosa and Acinetobacter baumannii

\begin{tabular}{|c|c|c|c|c|c|c|c|c|c|c|c|c|c|c|}
\hline \multirow[t]{2}{*}{ Isolates } & \multicolumn{6}{|c|}{$\begin{array}{l}\text { Number of isolates inhibited } \\
\text { at DFO-B }(\mathrm{mg} / \mathrm{mL})\end{array}$} & \multirow[t]{2}{*}{$\begin{array}{l}\text { Total } \\
\text { inhibited (\%) }\end{array}$} & \multicolumn{6}{|c|}{$\begin{array}{l}\text { Number of isolates inhibited at } \\
\text { DFO-B }(\mathrm{mg} / \mathrm{mL})+\text { ampicillin } \\
0.01 \mathrm{mg} / \mathrm{mL}\end{array}$} & \multirow[t]{2}{*}{$\begin{array}{l}\text { Total } \\
\text { inhibited (\%) }\end{array}$} \\
\hline & 0.5 & $\mathbf{I}$ & 2.5 & 5 & 7.5 & 10 & & 0.5 & $\mathbf{I}$ & 2.5 & 5 & 7.5 & 10 & \\
\hline MRSA $(n=20)$ & 0 & 0 & 0 & 0 & 1 & I & $2(10)$ & 0 & 0 & 0 & 2 & 4 & 4 & $10(50)$ \\
\hline MBL-producing $P$. aeruginos $a(n=15)$ & 0 & 0 & 0 & 1 & 1 & $\mathrm{I}$ & $3(20)$ & 0 & 0 & I & 1 & 1 & 2 & $5(33)$ \\
\hline MBL-producing A. baumannii $(n=15)$ & 0 & 0 & 1 & I & I & 1 & $4(27)$ & 0 & I & I & 1 & 1 & 2 & $6(40)$ \\
\hline
\end{tabular}

Notes: MIC was determined by adding DFO-B at different concentrations with or without ampicillin at $0.0 \mathrm{l} \mathrm{mg} / \mathrm{mL}$. The number of isolates inhibited at the end of $24 \mathrm{~h}$ at $37^{\circ} \mathrm{C}$ are shown. $\mathrm{n}=$ total number of isolates of each pathogen. Medium control showed no growth, whereas growth control, ampicillin control, and "Fe" control showed growth. (Data not shown.)

Abbreviations: DFO-B, deferoxamine-B; MBL, metallo- $\beta$-lactamase; MIC, minimum inhibitory concentration; MRSA, methicillin-resistant Staphylococcus aureus.

$24 \mathrm{~h}$, growth was observed at all concentrations of siderophores. Isolates exposed to siderophores individually and to siderophore+antibiotic combinations showed growth when transferred into a fresh growth medium without the test compounds, indicating bacteriostatic activity (data not shown).

Therefore, it was concluded that all the siderophore concentrations used were bacteriostatic.

When excess iron was supplemented in the MHB, the isolates could grow without any inhibition (data not shown).

\section{Turbidimetric assay}

This micro-broth kinetic assay was used to continuously monitor growth of four isolates each of MRSA and MBL producers. In every case, normal growth was seen in "growth control" and in "ampicillin control" wells. Figure 4 shows growth curves of a representative MRSA isolate in the presence of Exo-MS and ampicillin.

Figure 5 shows growth curves of a representative isolate of $P$. aeruginosa in the presence of Exo-MS and ampicillin.

Figure 6 shows growth curves of a representative Acinetobacter isolate in the presence of Exo-MS and ampicillin.

Growth curves of some isolates of MRSA, P. aeruginosa, and $A$. baumannii in the presence of DFO-B and ampicillin are shown in Figures S1-S3.

\section{Discussion}

This is a preliminary investigation to evaluate siderophores as adjuncts with antibiotics against commonly encountered drug-resistant pathogens such as MRSA and MBL-producing bacteria. Emergence of drug resistance in bacteria is mostly due to spontaneous mutations in their genes. Resistance in MRSA is primarily due to expression of the mecA gene, which encodes penicillin-binding protein (PBP2a), which has a low affinity for $\beta$-lactam antibiotics. ${ }^{8}$ Some of the drug resistance in Gram-negative bacteria can involve spontaneous point mutations such as loss of porins leading to impermeability of their outer membrane, or can be acquired through horizontal transfer of resistance genes. Upregulation of efflux pumps can also lead to drug resistance, for example, resistance to $\beta$-lactams including carbapenems. ${ }^{9}$

We hypothesize that iron deprivation caused by Exo-MS and DFO-B in bacteria may result in inhibition or inactivation of proteins and enzymes involved in vital functions. The siderophores may also act as facilitators for antibiotics across the cell membrane because of increase in permeability caused by iron deficiency. This could be the explanation why $50 \%-75 \%$ of MRSA isolates are inhibited when the siderophores are used in combination with antibiotics.

Another mechanism of drug resistance in Gram-negative bacteria is the production of MBLs. These are a diverse set of enzymes that are not susceptible to $\beta$-lactamase inhibitors and require zinc for their activity. When $\mathrm{Zn}^{2+}$ is chelated by EDTA, the MBLs are inactivated making the pathogens susceptible to $\beta$-lactam antibiotics. A similar mechanism may be responsible for the effect seen with the siderophores.

DFO-B binds iron in the $\mathrm{Fe}^{3+}$ form with an affinity constant of $\beta^{\mathrm{III}}=10^{30}$, and reduces it to $\mathrm{Fe}^{2+}$ with a lower affinity constant of $\beta^{\mathrm{II}}=10^{7.2}$, triggering the release of bound iron. The affinity of DFO-B for $\mathrm{Zn}^{2+}$ is $\beta^{\mathrm{II}}=10^{9.55}$, which is more than that for $\mathrm{Fe}^{2+}$. This affinity may be sufficient for the complex formation of DFO-B and $\mathrm{Zn}^{2+}$, given that the affinity constant of EDTA for $\mathrm{Zn}^{2+}$ is $\beta^{\mathrm{II}}=10^{16.5}$. Therefore, DFO-B may also deprive these MBL producers of $\mathrm{Zn}^{2+}$ making them susceptible to $\beta$-lactams. ${ }^{10}$

The results of MIC determination show that Exo-MS and DFO-B individually were inhibitory to some isolates, which was not observed in the disc diffusion method. In liquid cultures, siderophores probably get easier access to $\mathrm{Fe}^{3+}$, leading to better sequestration of iron. This may deprive the organisms of iron and decrease the activity of critical proteins that are Fe-dependent. One such protein is 
A

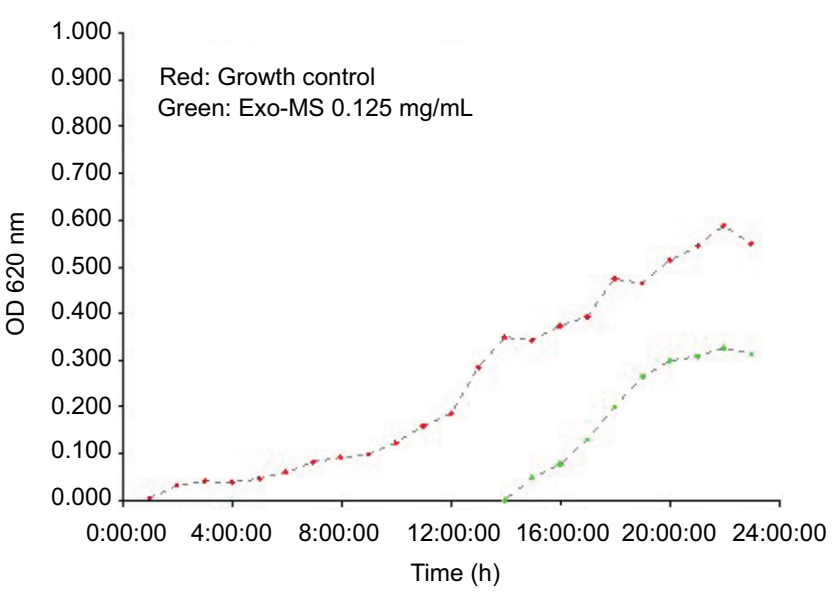

C

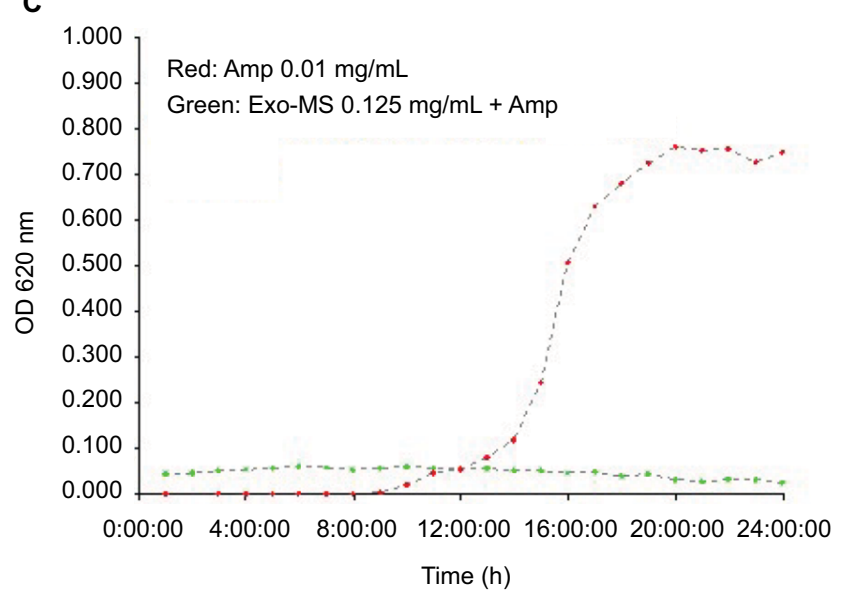

B

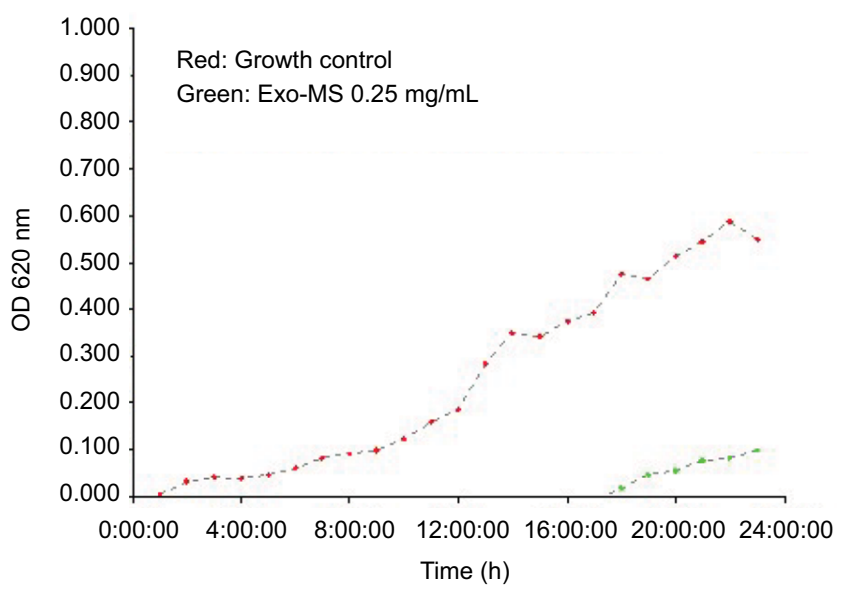

D

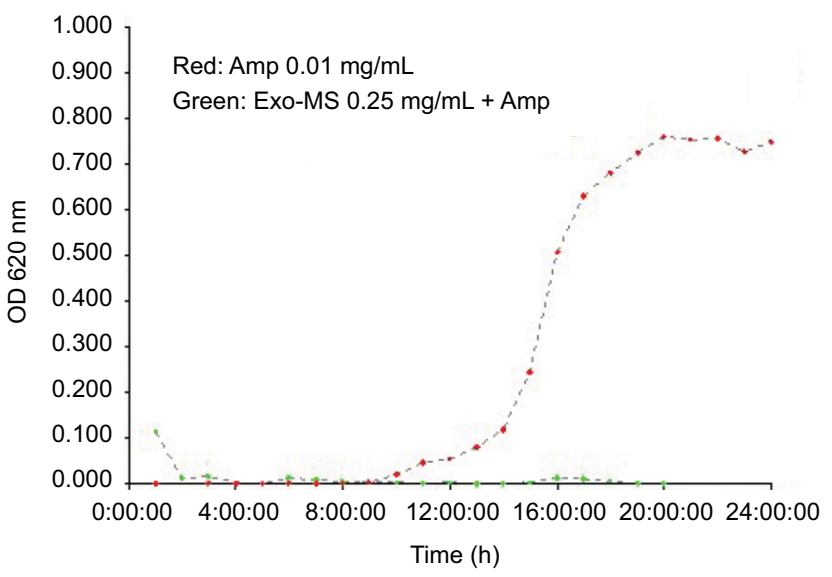

Figure 4 Growth curves of methicillin-resistant Staphylococcus aureus in the presence of Exo-MS.

Notes: (A) and (B) plot in red: growth curves of the isolate in medium alone and plot in green show curves in the presence of Exo-MS at 0.125 and $0.25 \mathrm{mg} / \mathrm{mL}$, respectively; (C) and (D) plot in red: growth curves of the isolate in the presence of ampicillin $0.01 \mathrm{mg} / \mathrm{mL}$ and plot in green show curves in the presence of Exo-MS 0.125 and $0.25 \mathrm{mg} / \mathrm{mL}$, respectively, along with ampicillin $0.01 \mathrm{mg} / \mathrm{mL}$.

Abbreviations: Amp, ampicillin; Exo-MS, exochelin-MS; OD, optical density.

ribonucleotide reductase that is involved in DNA synthesis. Cytochromes are examples of other iron-dependent proteins that are essential for energy metabolism. If any of these get affected, multiplication of the organism may be arrested.

In the turbidimetric growth assays, Exo-MS and DFO-B prolonged the lag time along with a reduction in the cell numbers, which was reflected in the lesser OD values at the end of $24 \mathrm{~h}$. The combination of Exo-MS+ampicillin and DFO-B+ampicillin had a synergistic effect as there was total inhibition of the isolates with OD readings close to zero after $24 \mathrm{~h}$. These assays validated the inhibitory effects seen in the MIC determination of Exo-MS, DFO-B, and their combination with antibiotics.

There were a few isolates that were unaffected by siderophore+antibiotic combinations. These isolates perhaps have the capability of acquiring iron from exogenous chelators because of the existence of as yet unknown and uncharacterized iron-uptake systems. For instance, it has been shown that $P$. aeruginosa has iron-uptake ability from multiple siderophores under conditions of iron deficiency. ${ }^{11}$

Earlier studies have shown that ascorbic acid is required for enhancing siderophore activity. For example, van Asbeck et a ${ }^{12}$ have demonstrated inhibitory activity of DFO-B against Gram-positive and Gram-negative bacteria in combination with antibiotics only when ascorbic acid was present. In other studies, inhibitory effects of DFO-B and synthetic iron chelators against pathogens including $S$. aureus were tested. ${ }^{13,14}$ However, none of these studies evaluated the effect of iron chelators+antibiotic combinations, nor did they use drug-resistant isolates. ${ }^{12-14}$

We did not observe any enhancement of siderophore activity by ascorbic acid (data not shown). Our study did not support the hypothesis of the toxic radical formation, and the inhibition was simply due to iron chelation. The 
A

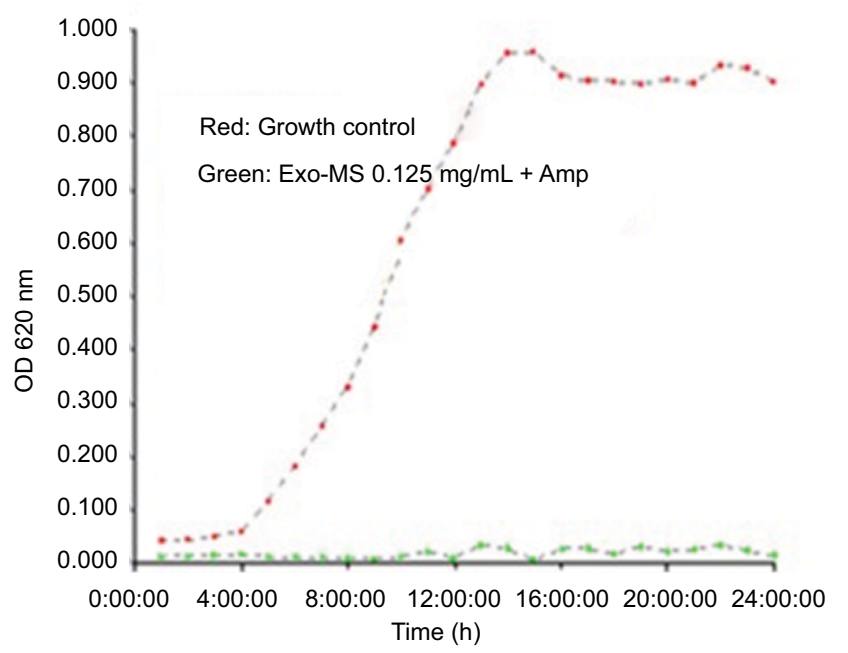

B

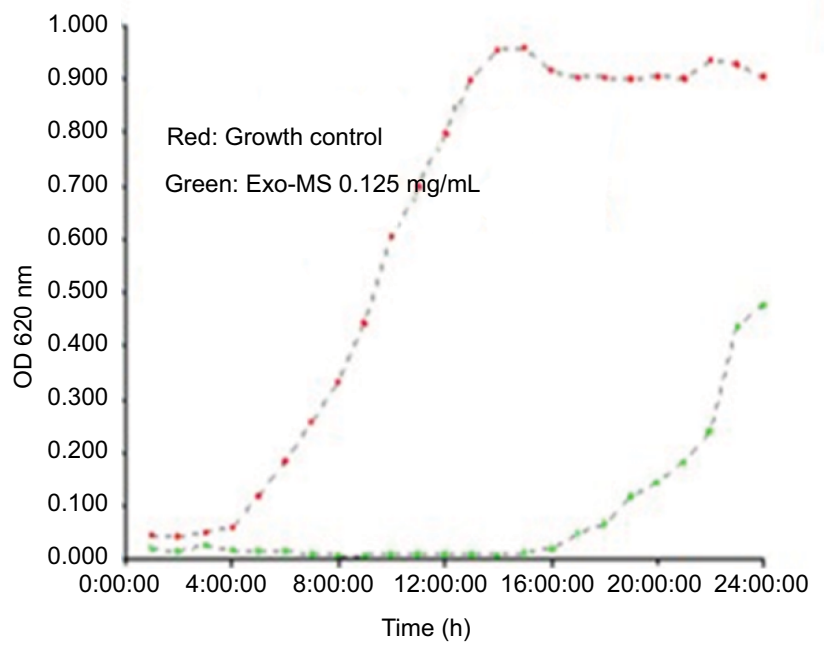

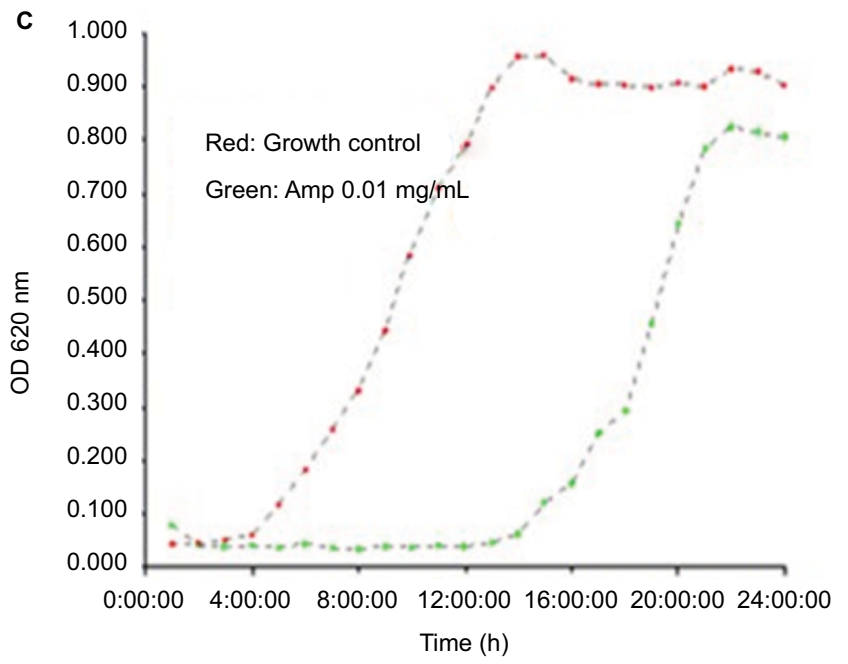

Figure 5 Growth curves of an isolate of metallo- $\beta$-lactamase-producing Pseudomonas aeruginosa in the presence of Exo-MS.

Notes: Plot in red: growth curves of the isolate in medium alone. Plot in green show growth curves: $(\mathbf{A})$ in the presence of Exo-MS at $0.125 \mathrm{mg} / \mathrm{mL}+$ ampicillin $0.0 \mathrm{I} \mathrm{mg} / \mathrm{mL}$, (B) only Exo-MS at $0.125 \mathrm{mg} / \mathrm{mL}$, and (C) only ampicillin $0.01 \mathrm{mg} / \mathrm{mL}$.

Abbreviations: Amp, ampicillin; Exo-MS, exochelin-MS; OD, optical density.

drug-resistant isolates grew normally when excess iron was added to saturate siderophores and free iron made available in the medium. This indicated that the growth inhibition was not due to toxicity caused by excess intracellular iron, as has been suggested elsewhere. ${ }^{15}$

We have reported in a pioneering study that similar concentrations of Exo-MS and DFO-B were inhibitory to multidrug-resistant Mycobacterium tuberculosis (Mtb) isolates by the Mycobacteria growth indicator tube-drug susceptibility test method. ${ }^{16}$ It has provided a "proof of concept" that exogenous siderophores could be valuable additions to fight drug-resistant $M t b$. Importantly, in a parallel study, we have also shown that the same concentrations of siderophores did not harm normal mammalian cells in vitro. ${ }^{6}$

\section{Conclusion}

Siderophores can be employed effectively by themselves or with antibiotics to inhibit drug-resistant pathogenic bacteria. Exo-MS concentration up to $0.5 \mathrm{mg} / \mathrm{mL}$ hindered growth of $75 \%$ of MRSA isolates and $30 \%-50 \%$ of MBL-producing P. aeruginosa and $A$. baumannii isolates. DFO-B at relatively higher concentrations had bacteriostatic effect on $30 \%-50 \%$ of the isolates tested.

\section{Acknowledgments}

We would like to acknowledge the Department of Microbiology for laboratory facilities at Sir Hurkisondas Nurrotumdas Hospital and Medical Research Society, Mumbai. We thank the Department of Microbiology, St Xavier's College, Mumbai, 
A

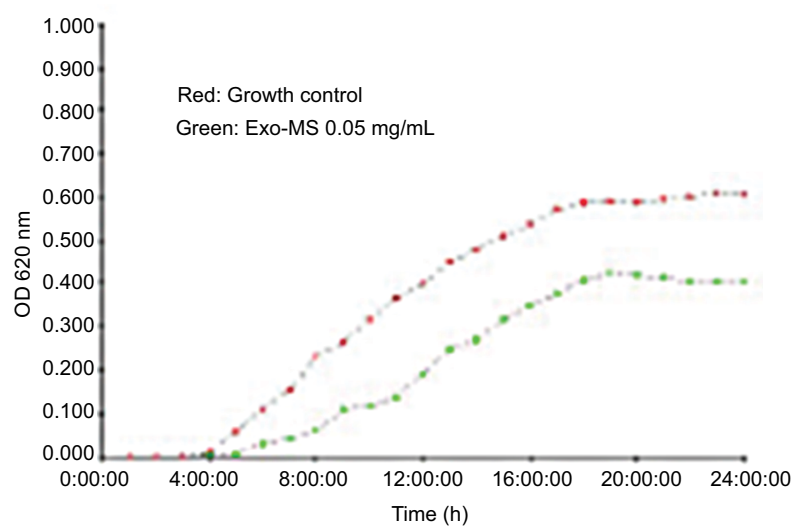

C

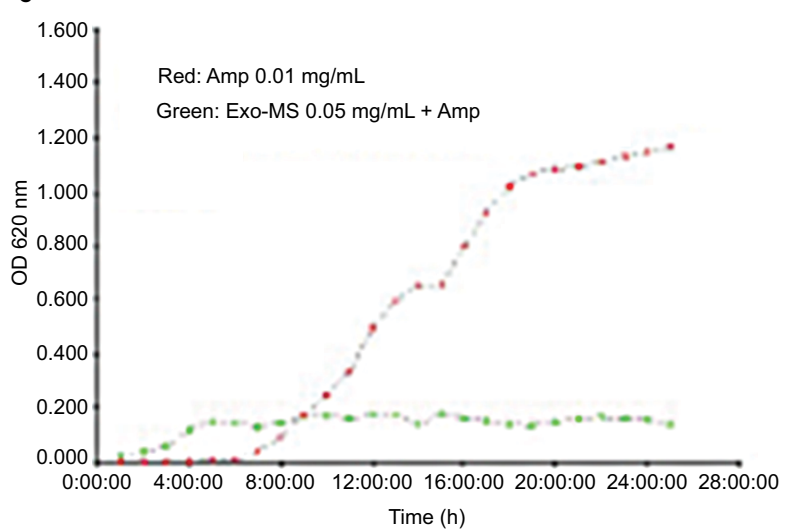

B

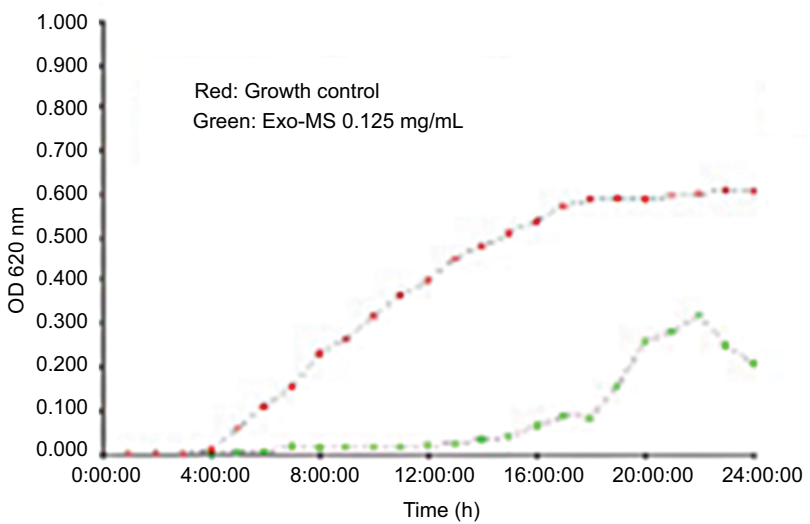

D

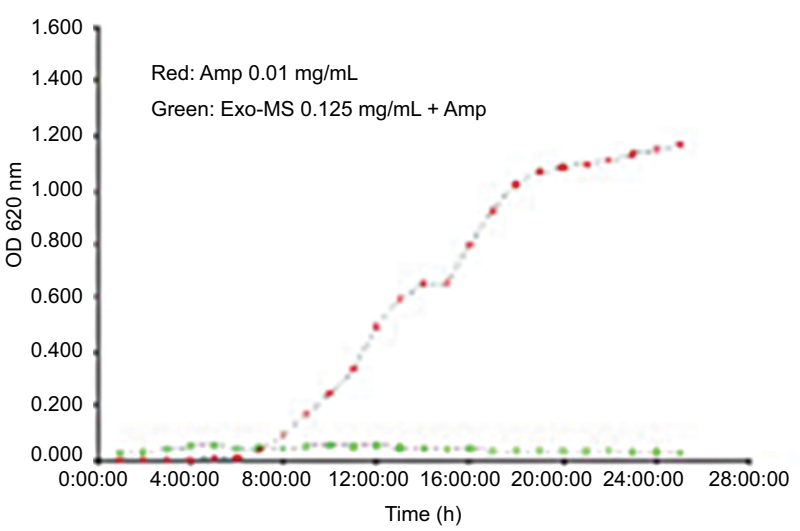

Figure 6 Growth curves of metallo- $\beta$-lactamases-producing Acinetobacter baumannii in the presence of Exo-MS.

Notes: (A) and (B) plot in red: growth curves of the isolate in medium alone and plot in green show curves in the presence of Exo-MS at 0.05 and $0.125 \mathrm{mg} / \mathrm{mL}$, respectively; (C) and (D) plot in red: growth curves of the isolate in the presence of ampicillin $0.01 \mathrm{mg} / \mathrm{mL}$ and plot in green show curves in the presence of Exo-MS at 0.05 and $0.125 \mathrm{mg} / \mathrm{mL}$, respectively, in combination with ampicillin $0.01 \mathrm{mg} / \mathrm{mL}$.

Abbreviations: Amp, ampicillin; Exo-MS, exochelin-MS; OD, optical density.

for permitting the use of Epoch 2 instrument. We also thank Dr Vishwas Sarangdhar for his critical comments and help with the manuscript. This work was funded by Sir Hurkisondas Nurrotumdas Hospital and Medical Research Society, Mumbai.

\section{Disclosure}

The authors report no conflicts of interest in this work.

\section{References}

1. Datta P, Gulati N, Singla N, et al. Evaluation of various methods for the detection of methicillin-resistant Staphylococcus aureus strains and susceptibility patterns. J Med Microbiol. 2011;60(Pt 11):1613-1616.

2. Duran N, Ozer B, Duran GG, Onlen Y, Demir C. Antibiotic resistance genes and susceptibility patterns in staphylococci. Indian J Med Res. 2012;135(3):389-396.

3. Skov R, Smyth R, Larsen AR, et al. Phenotypic detection of methicillin resistance in Staphylococcus aureus by disk diffusion testing and E test on Mueller-Hinton agar. J Clin Microbiol. 2006;44(12):4395-4399.

4. Marchiaro P, Mussi MA, Ballerini V, et al. Sensitive EDTA-based microbiological assays for detection of metallo- $\beta$-lactamases in nonfermentative Gram-negative bacteria. J Clin Microbiol. 2005;43(11): $5648-5652$.
5. Lee K, Lim YS, Yong D, Yum JH, Chong Y. Evaluation of the Hodge test and the imipenem-EDTA double-disk synergy test for differentiating metallo- $\beta$-lactamase-producing isolates of Pseudomonas spp. and Acinetobacter spp. J Clin Microbiol. 2003;41(10):4623-4629.

6. Gokarn K, Sarangdhar V, Pal RB. Effect of microbial siderophores on mammalian non-malignant and malignant cell lines. BMC Complement Altern Med. 2017;17:145-156.

7. CLSI Manual of Antimicrobial Susceptibility Testing. Available from: http://www.asm.org/ccLibraryFiles/FILENAME/000000002484/ Manual\%20of\%20Antimicrobial\%20Susceptibility\%20Testing.pdf. Accessed November 20, 2015.

8. Stapleton PD, Taylor PW. Methicillin resistance in Staphylococcus aureus: methicillin resistance. Sci Prog. 2007;85(1):1-14.

9. Papp-Wallace KM, Endimiani A, Taracila MA, Bonomo RA. Carbapenems: past, present, and future. Antimicrob Agents Chemother. 2011;55(11):4943-4960.

10. Hernlem BJ, Vane LM, Sayles GD. Stability constants for complexes of the siderophore desferrioxamine B with selected heavy metal cations. Inorg Chim Acta. 2007;244(2):179-184.

11. Visca P, Bonch C, Minandri F, Frangipani E, Imperi F. The dual personality of iron chelators: growth inhibitors or promoters. Antimicrob Agents Chemother. 2013;57(5):2432-2433.

12. van Asbeck BS, Marcelis JH, van Kats JH, Jaarsma EY, Verhoef J. Synergy between the iron-chelator deferoxamine and the antimicrobial agents, gentamicin, chloramphenicol, cefalothin, cefotiam and cefsulodin. Europ J Clin Microbiol. 1983;2(5):432-438. 
13. Hartzen SH, Frimodt-Møller N, Thomsen VF. In vitro activity of deferoxamine alone and in combination with ascorbic acid on Staphylococcus aureus. APMIS. 1989;97(5):419-424.

14. Thompson MG, Corey B. W, Si Y, Craft DW, Zurawski DV. Antibacterial activities of iron chelators against common nosocomial pathogens. Antimicrob Agents Chemother. 2012;56(10):5419-5421.
15. Andrews SC, Robinson AK, Rodriguez-Quinones F. Bacterial iron homeostasis. FEMS Microbiol Rev. 2003;27(2-3):215-237.

16. Gokarn K, Pal RB. Preliminary evaluation of anti-tuberculosis potential of siderophores against drug-resistant Mycobacterium tuberculosis by mycobacteria growth indicator tube-drug susceptibility test. $B M C$ Complement Altern Med. 2017;17(1):161-168. 


\section{Supplementary material \\ Results}

Identification of methicillin-resistant Staphylococcus aureus isolates:

- The Clinical \& Laboratory Standards Institute guidelines for interpretation of inhibition zones for oxacillin and cefoxitin are shown in Table S1.

\section{Identification of metallo- $\beta$-lactamase producers}

In EDTA+imipenem/ceftazidime combination assay, cell extracts of the clinical isolates of Pseudomonas aeruginosa and Acinetobacter baumannii were used to assess the growth of indicator Escherichia coli strain ATCC 25922. If growth was observed around discs containing crude enzyme extract as well as $\mathrm{ZnSO}_{4}+$ crude enzyme extract, it showed the presence of carbapenemases in the extract of the isolates. Production of metallo- $\beta$-lactamases (MBLs) was confirmed when E. coli ATCC 25922 was inhibited by EDTA+crude enzyme extract of the isolates. Buffer alone showed inhibition as expected.

In EDTA-double disc synergy test, presence of expanded inhibition zone between EDTA and antibiotic discs confirmed that the isolate was an MBL producer.

In the modified Hodge test, isolate showing "cloverleaf" growth pattern of E. coli 25922 was considered as MBL producers.

Based on all the tests, 20 isolates of MRSA, 15 isolates of MBL-producing P. aeruginosa, and 15 isolates of MBLproducing $A$. baumannii were used to determine the effect of siderophores.

Table SI Interpretive criteria $(\mathrm{mm})$ for oxacillin and cefoxitin disc diffusion test

\begin{tabular}{|c|c|c|c|c|c|c|}
\hline \multirow[t]{2}{*}{ Isolate } & \multicolumn{3}{|l|}{ Oxacillin } & \multicolumn{2}{|l|}{ Cefoxitin } & \multirow[t]{2}{*}{ Resistant } \\
\hline & Susceptible & Intermediate & Resistant & Susceptible & Intermediate & \\
\hline Staphylococcus aureus & $\geq 13 \mathrm{~mm}$ & $\mathrm{I} \mathrm{I}-12 \mathrm{~mm}$ & $\leq 10 \mathrm{~mm}$ & $\geq 20 \mathrm{~mm}$ & - & $\leq 19 \mathrm{~mm}$ \\
\hline
\end{tabular}

Note: The $S$. aureus isolates found to be resistant to these two antibiotics as per this standard chart were tested further. The isolates that showed minimum inhibitory concentrations of oxacillin E-test $\geq 4 \mu \mathrm{g} / \mathrm{mL}$ and showed agglutination in the latex agglutination test were identified as methicillinresistant Staphylococcus aureus.

Table S2 Susceptibility of methicillin-resistant Staphylococcus aureus isolates to siderophores and antibiotics

\begin{tabular}{|c|c|c|c|c|c|c|c|c|}
\hline \multirow[t]{2}{*}{ Isolate No } & \multicolumn{8}{|c|}{ Zone of inhibition (diameter in $\mathbf{m m}$ ) } \\
\hline & Amp & Amp + DFO-B & Amp + Exo-MS & Cdr & Cdr + DFO-B & Cdr + Exo-MS & DFO-B & Exo-MS \\
\hline I & 20 & 20 & 20 & - & - & 15 & - & - \\
\hline 2 & - & - & 13 & 19 & 19 & 19 & - & - \\
\hline 3 & - & - & 18 & 17 & 17 & 17 & - & - \\
\hline 4 & - & - & 20 & 15 & 15 & 12 & - & - \\
\hline 5 & - & 10 & 10 & 18 & 21 & 20 & - & - \\
\hline 6 & - & - & - & 15 & 15 & 15 & - & - \\
\hline 7 & - & - & 30 & - & - & 23 & - & - \\
\hline 8 & - & 24 & 20 & 13 & 13 & 10 & - & - \\
\hline 9 & - & - & - & - & - & - & - & - \\
\hline 10 & - & 23 & 20 & - & - & 22 & - & - \\
\hline II & - & 20 & 15 & 16 & 16 & 16 & - & - \\
\hline 12 & - & 15 & 15 & 14 & 14 & - & - & - \\
\hline 13 & - & 26 & 22 & 17 & 16 & 15 & - & - \\
\hline 14 & - & 19 & 15 & 19 & 19 & 20 & - & - \\
\hline 15 & - & 11 & 10 & - & 15 & 16 & - & - \\
\hline 16 & - & - & 23 & - & - & 25 & - & - \\
\hline 17 & - & 14 & - & 18 & 18 & 19 & - & - \\
\hline 18 & - & 27 & - & - & - & 24 & - & - \\
\hline 19 & - & - & 10 & 15 & 13 & 23 & - & - \\
\hline 20 & - & - & 10 & 20 & 20 & 20 & - & - \\
\hline
\end{tabular}

Note: Zone of inhibition on Mueller-Hinton agar plates incubated at $37^{\circ} \mathrm{C}$ for $24 \mathrm{~h}$. (-), No inhibition.

Abbreviations: Amp, ampicillin; Cdr, cefdinir; DFO-B, deferoxamine-B; Exo-MS, exochelin-MS. 
Table S3 Susceptibility of metallo- $\beta$-lactamase-producing Pseudomonas aeruginosa isolates to siderophores and antibiotics

\begin{tabular}{|c|c|c|c|c|c|c|c|c|c|c|c|}
\hline \multirow{2}{*}{$\begin{array}{l}\text { Isolate } \\
\text { no. }\end{array}$} & \multicolumn{11}{|c|}{ Zone of inhibition (diameter in $\mathbf{m m}$ ) } \\
\hline & Amp & $\begin{array}{l}\text { Amp + } \\
\text { DFO-B }\end{array}$ & $\begin{array}{l}\text { Amp + } \\
\text { Exo-MS }\end{array}$ & Ipm & $\begin{array}{l}\text { Ipm + } \\
\text { DFO-B }\end{array}$ & $\begin{array}{l}\text { Ipm + } \\
\text { Exo-MS }\end{array}$ & DFO-B & $\begin{array}{l}\text { Exo- } \\
\text { MS }\end{array}$ & Mrp & $\begin{array}{l}\text { Mrp + } \\
\text { DFO-B }\end{array}$ & $\begin{array}{l}\text { Mrp + } \\
\text { Exo-MS }\end{array}$ \\
\hline $\mathrm{I}$ & 20 & 20 & - & 10 & 40 & 34 & - & - & 15 & 22 & 23 \\
\hline 2 & - & 23 & 16 & 15 & 35 & 15 & 26 & - & 12 & 15 & 32 \\
\hline 3 & 18 & 19 & 20 & - & - & 28 & - & - & - & 30 & 12 \\
\hline 4 & - & 19 & 20 & - & 26 & 13 & - & - & 10 & 40 & 35 \\
\hline 5 & - & - & - & 15 & 15 & 20 & - & - & 13 & 13 & 12 \\
\hline 6 & - & - & - & - & - & 15 & - & - & 15 & 15 & 16 \\
\hline 7 & - & - & - & - & 20 & 20 & - & - & 15 & 15 & 15 \\
\hline 8 & - & - & - & 10 & 10 & 10 & - & - & 10 & 30 & 30 \\
\hline 9 & - & - & - & - & 24 & & - & - & 10 & 30 & 35 \\
\hline 10 & 15 & 10 & 10 & - & 44 & 34 & - & - & 12 & 12 & 12 \\
\hline II & - & 22 & 22 & 22 & 20 & 20 & - & - & 14 & 14 & 14 \\
\hline 12 & - & 14 & - & - & 22 & - & - & - & 12 & 16 & 26 \\
\hline 13 & - & - & - & - & 35 & - & - & - & 14 & 20 & 20 \\
\hline 14 & - & - & - & 13 & 13 & 13 & - & - & 15 & 12 & 20 \\
\hline 15 & - & 20 & 34 & 26 & 27 & 33 & - & - & 12 & 10 & 10 \\
\hline
\end{tabular}

Note: Zone of inhibition on Mueller-Hinton agar plates incubated at $37^{\circ} \mathrm{C}$ for 24 hr. $(-)=$ No inhibition.

Abbreviations: DFO-B, deferoxamine-B; Exo-MS, exochelin-MS; Ipm, imipenem; Mrp, meropenem.

Table S4 Susceptibility of metallo- $\beta$-lactamase-producing Acinetobacter baumannii isolates to siderophores and antibiotics

\begin{tabular}{|c|c|c|c|c|c|c|c|c|c|c|c|}
\hline \multirow{2}{*}{$\begin{array}{l}\text { Isolate } \\
\text { no. }\end{array}$} & \multicolumn{11}{|c|}{ Zone of inhibition (diameter in $\mathrm{mm}$ ) } \\
\hline & Amp & $\begin{array}{l}\text { Amp + } \\
\text { DFO-B }\end{array}$ & $\begin{array}{l}\text { Amp + } \\
\text { Exo-MS }\end{array}$ & Ipm & $\begin{array}{l}\text { Ipm + } \\
\text { DFO-B }\end{array}$ & $\begin{array}{l}\text { Ipm + } \\
\text { Exo-MS }\end{array}$ & DFO-B & $\begin{array}{l}\text { Exo- } \\
\text { MS }\end{array}$ & Mrp & $\begin{array}{l}\text { Mrp + } \\
\text { DFO-B }\end{array}$ & $\begin{array}{l}\text { Mrp + } \\
\text { Exo-MS }\end{array}$ \\
\hline 1 & - & - & - & - & 23 & 15 & - & - & 15 & 15 & 25 \\
\hline 2 & - & - & 24 & 15 & 15 & 29 & - & - & 14 & 21 & 14 \\
\hline 3 & - & 19 & 19 & 15 & 23 & 14 & 25 & - & 10 & 32 & 30 \\
\hline 4 & - & 24 & - & 15 & 15 & 15 & 15 & - & 15 & 50 & 50 \\
\hline 5 & - & - & - & - & 16 & 31 & - & - & 12 & 13 & 14 \\
\hline 6 & - & - & - & 15 & 13 & 14 & - & - & 13 & 23 & 23 \\
\hline 7 & 22 & 35 & 30 & - & 38 & 12 & - & - & 15 & 28 & 28 \\
\hline 8 & 12 & 12 & 14 & 14 & 30 & 28 & - & - & 13 & 25 & 30 \\
\hline 9 & - & - & 15 & 13 & 13 & 13 & - & - & 12 & 11 & 14 \\
\hline 10 & 16 & 23 & 23 & 12 & 22 & 10 & - & - & - & 30 & 33 \\
\hline 11 & 20 & - & 15 & 8 & 38 & 25 & - & - & - & 20 & 26 \\
\hline 12 & - & - & - & 20 & 10 & 10 & - & - & 10 & 35 & 35 \\
\hline 13 & - & 11 & 10 & 15 & 28 & 30 & - & - & 15 & 27 & 19 \\
\hline 14 & 10 & 11 & 13 & 40 & 40 & 40 & - & - & 10 & 10 & 32 \\
\hline 15 & - & - & - & 9 & - & 6 & - & - & - & - & - \\
\hline
\end{tabular}

Note: Zone of inhibition on Mueller-Hinton agar plates incubated at $37^{\circ} \mathrm{C}$ for 24 h. (-), No inhibition.

Abbreviations: DFO-B, deferoxamine-B; Exo-MS, exochelin-MS; Ipm, imipenem; Mrp, meropenem. 
A

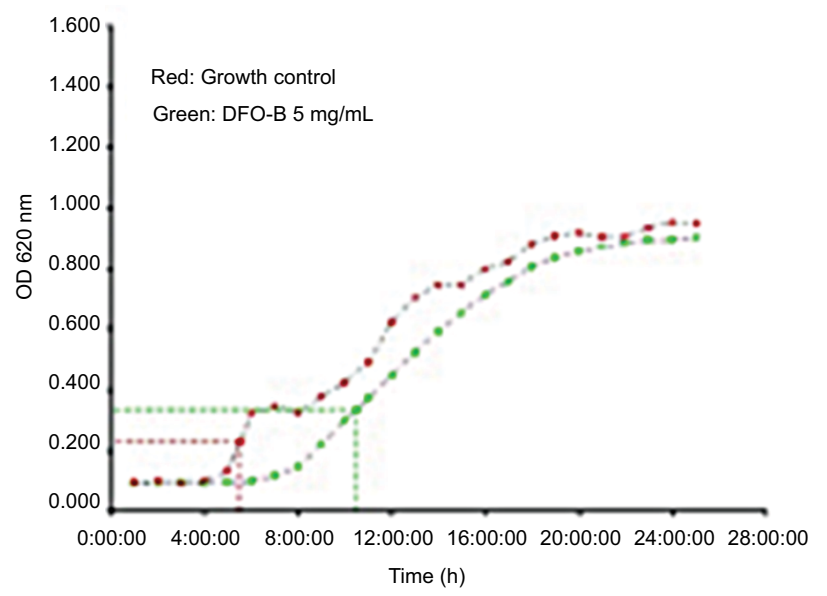

C

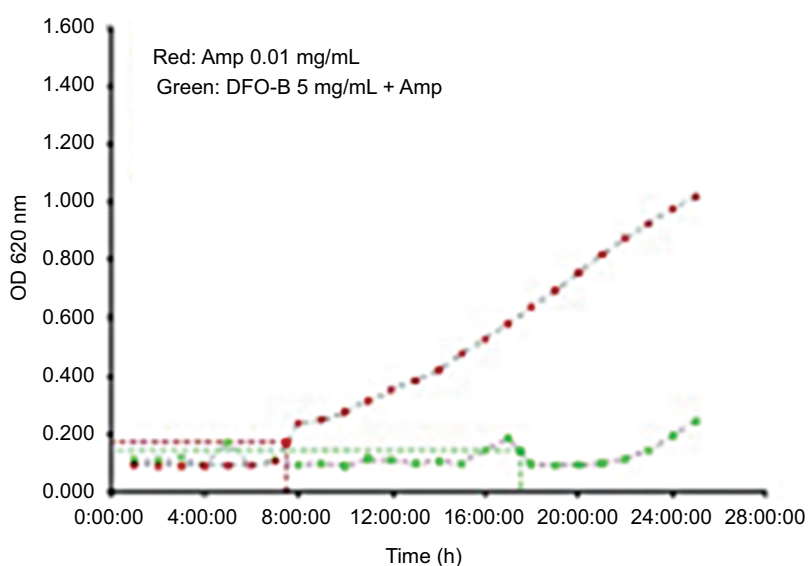

B

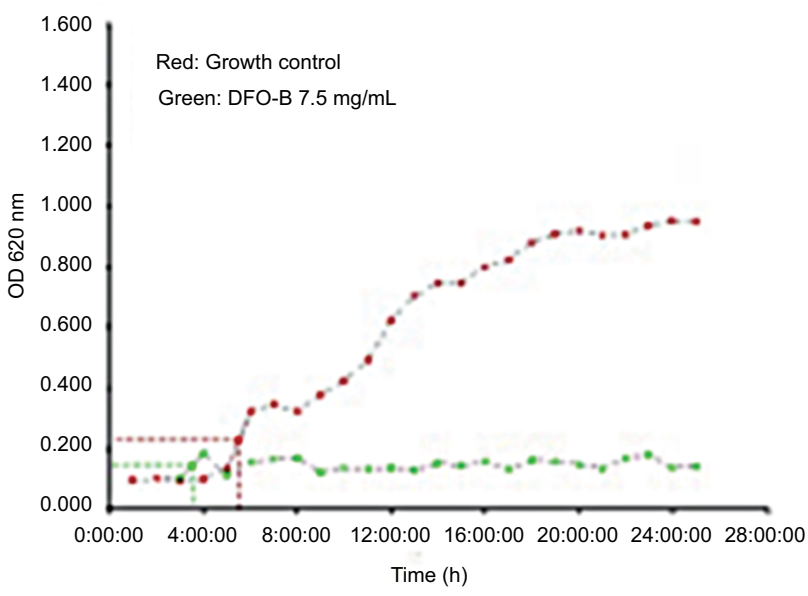

D

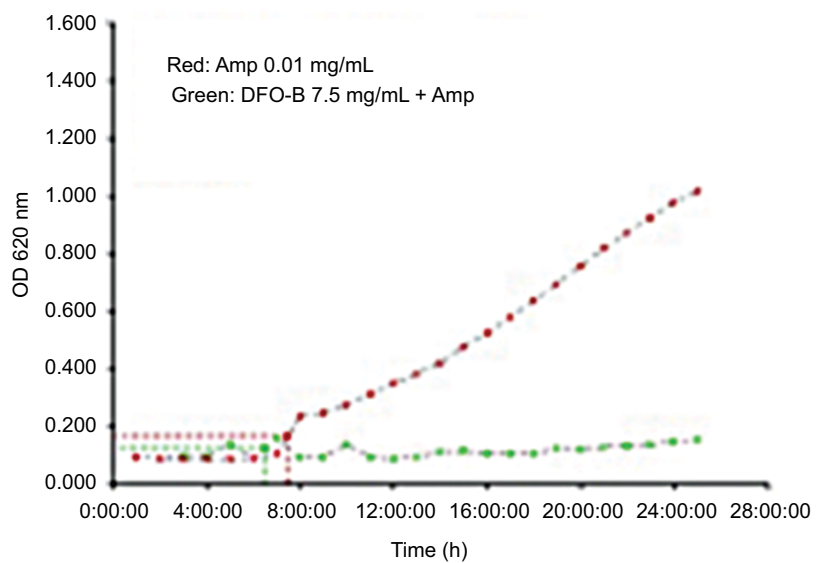

Figure SI Growth curves of methicillin-resistant Staphylococcus aureus in the presence of DFO-B.

Notes: (A) and (B) plot in red: growth curves of the isolate in medium alone and plot in green show curves in the presence of DFO-B at 5 and $7.5 \mathrm{mg} / \mathrm{mL}$, respectively. (C) and (D) plot in red: growth curves of the isolate in the presence of ampicillin $0.01 \mathrm{mg} / \mathrm{mL}$ and plot in green show curves in the presence of DFO-B at 5 and $7.5 \mathrm{mg} / \mathrm{mL}$, respectively, along with ampicillin $0.01 \mathrm{mg} / \mathrm{mL}$.

Abbreviations: Amp, ampicillin; DFO-B, deferoxamine-B. 
A

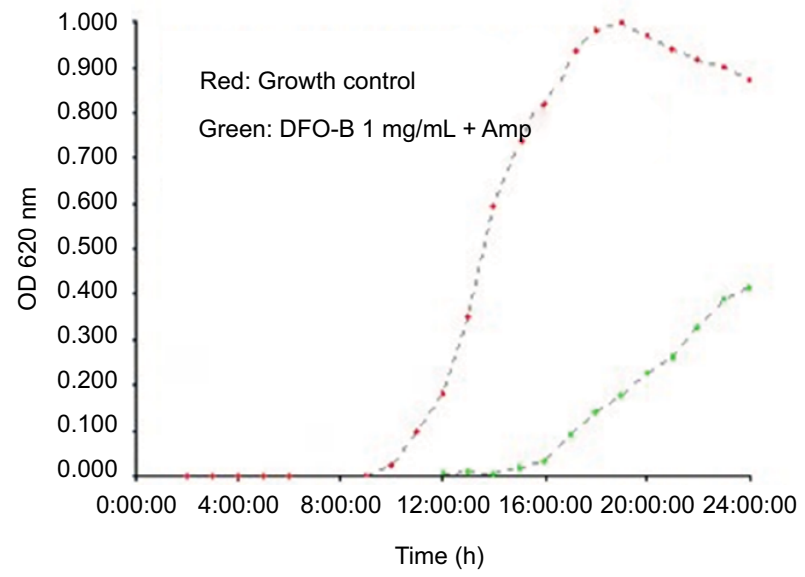

C

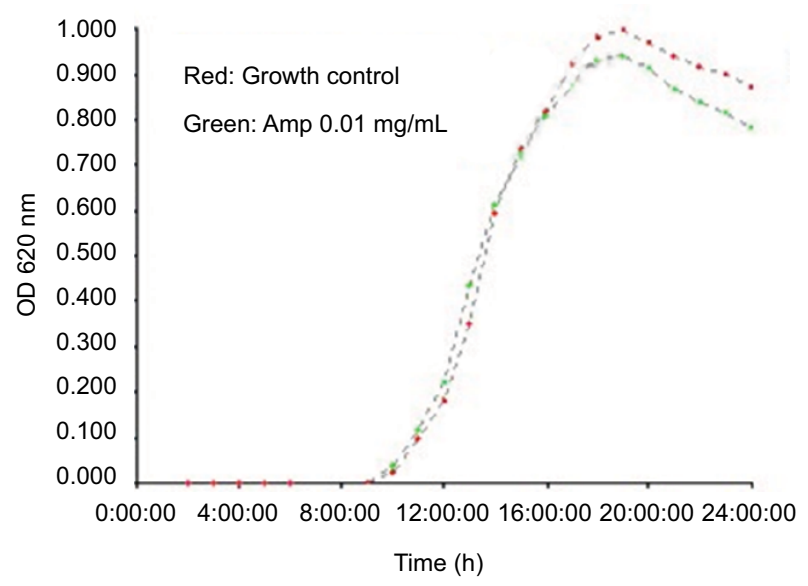

E

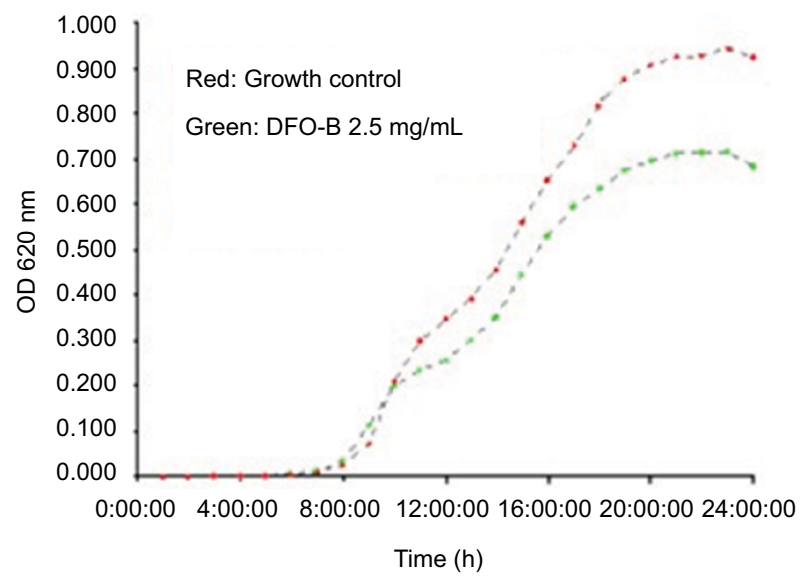

B

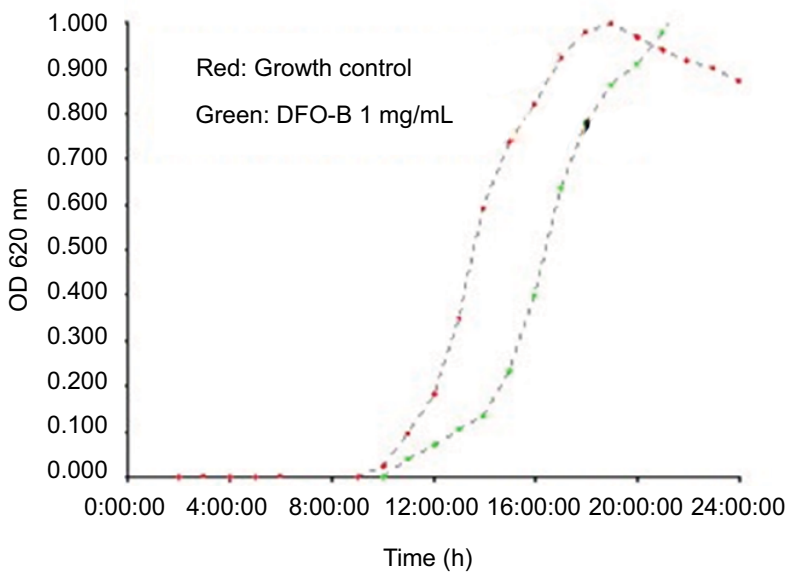

D

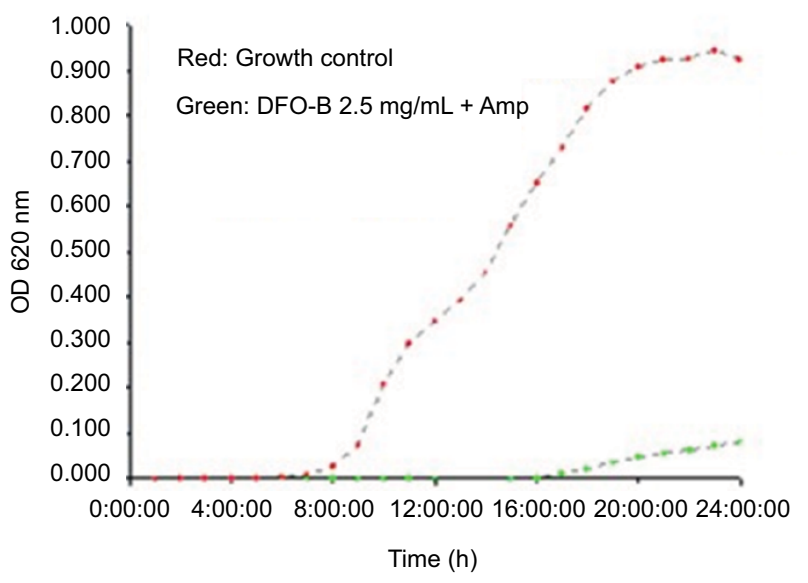

$\mathbf{F}$

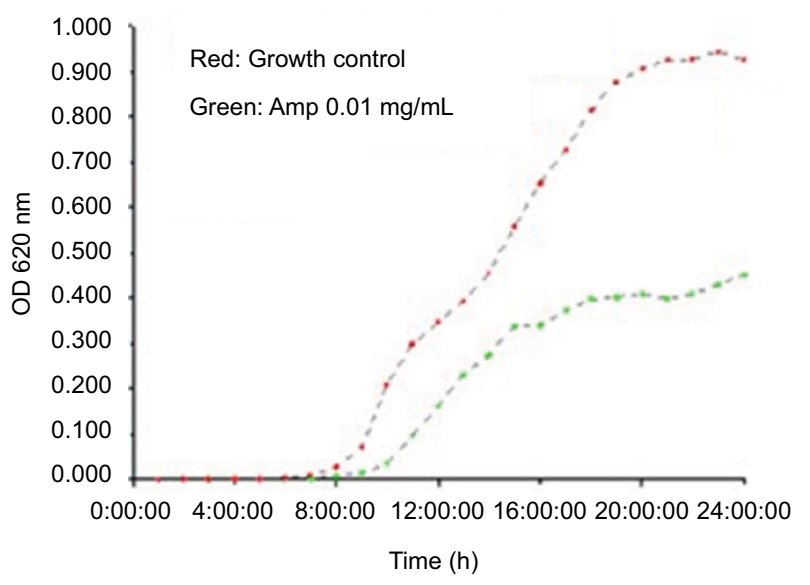

Figure S2 Growth curves of two isolates of Pseudomonas aeruginosa in the presence of DFO-B

Notes: Plot in red: growth curves of both the isolates in medium alone. Plot in green shows growth curves for Isolate I: (A) green curves in the presence of DFO-B at $1 \mathrm{mg} / \mathrm{mL}+$ ampicillin $0.01 \mathrm{mg} / \mathrm{mL}$, (B) only DFO-B at I mg/mL, and (C) only ampicillin $0.01 \mathrm{mg} / \mathrm{mL}$. Plot in green shows growth curves for Isolate 2: (D) green curves in the presence of DFO-B $2.5 \mathrm{mg} / \mathrm{mL}$ + ampicillin $0.01 \mathrm{mg} / \mathrm{mL}$, (E) only DFO-B at $2.5 \mathrm{mg} / \mathrm{mL}$, and (F) only ampicillin $0.01 \mathrm{mg} / \mathrm{mL}$.

Abbreviations: Amp, ampicillin; DFO-B, deferoxamine-B; OD, optical density. 
A

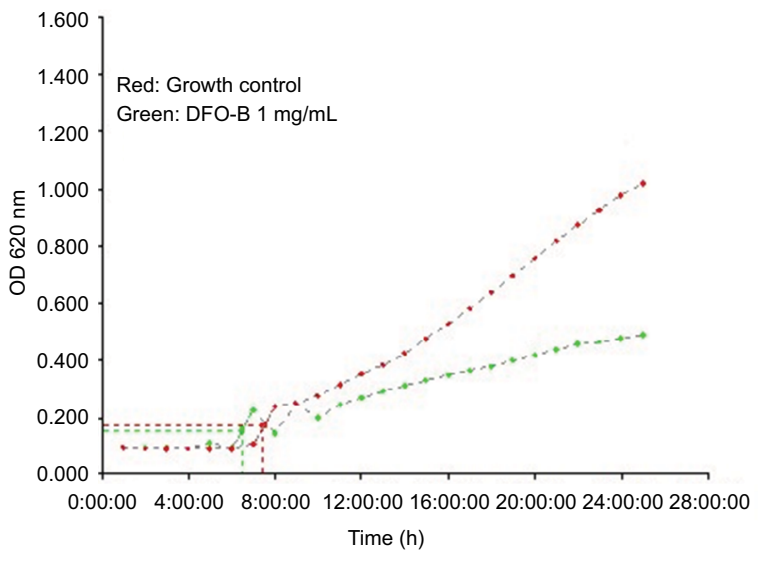

C

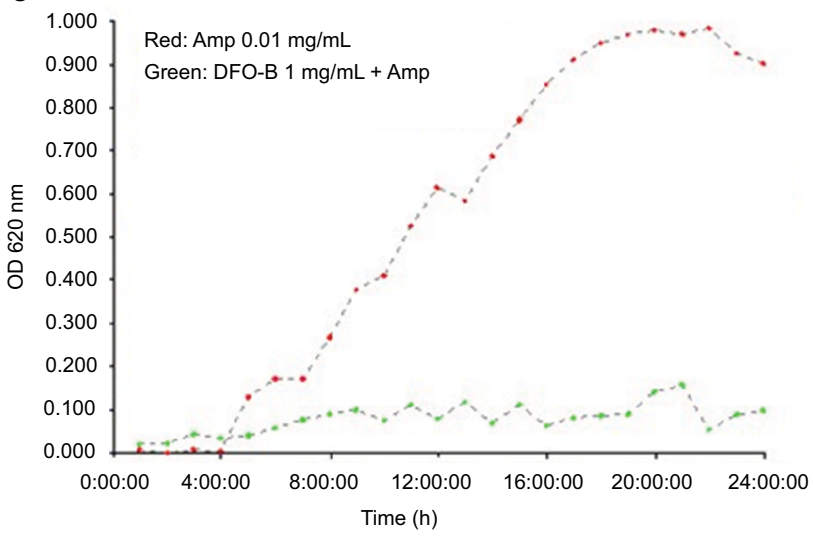

B

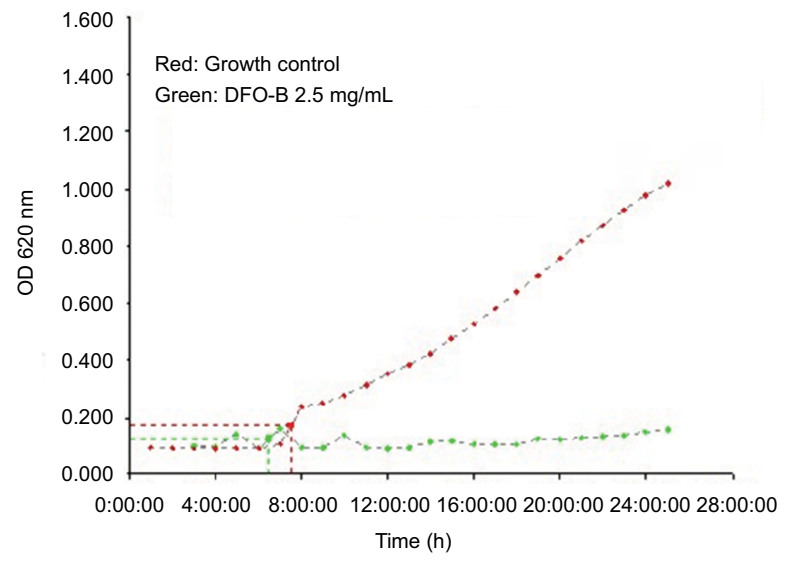

D

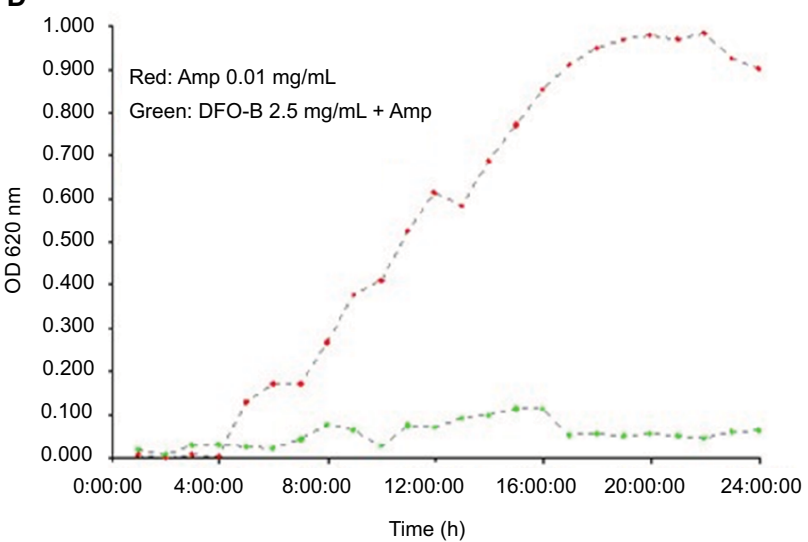

Figure S3 Growth curves of MBL-producing Acinetobacter baumannii in the presence of DFO-B

Notes: (A) and (B) plot in red: growth curves of the isolate in medium alone and plot in green shows curves in the presence of DFO-B at I and $2.5 \mathrm{mg} / \mathrm{mL}$, respectively; (C) and (D) plot in red: growth curves of the isolate in the presence of ampicillin $0.01 \mathrm{mg} / \mathrm{mL}$ and plot in green shows curves in the presence of DFO-B at 2.5 and I mg/mL, respectively, in combination with ampicillin $0.01 \mathrm{mg} / \mathrm{mL}$.

Abbreviations: Amp, ampicillin; DFO-B, deferoxamine-B; MBL, metallo- $\beta$-lactamase; OD, optical density.

Infection and Drug Resistance

\section{Publish your work in this journal}

Infection and Drug Resistance is an international, peer-reviewed openaccess journal that focuses on the optimal treatment of infection (bacterial, fungal and viral) and the development and institution of preventive strategies to minimize the development and spread of resistance. The journal is specifically concerned with the epidemiology of antibiotic

\section{Dovepress}

resistance and the mechanisms of resistance development and diffusion in both hospitals and the community. The manuscript management system is completely online and includes a very quick and fair peerreview system, which is all easy to use. Visit http://www.dovepress.com/ testimonials.php to read real quotes from published authors.

Submit your manuscript here: https://www.dovepress.com/infection-and-drug-resistance-journal 